\title{
Aplikasi Pencarian dan Pemesanan Hotel di Kota Pagar Alam Berbasis Web
}

\author{
Febriansyah $^{1^{*}}$, Siti Muntari² \\ ${ }^{1}$ Program Studi Teknik Informatika, Sekolah Tinggi Teknologi Pagaralam \\ 2Program Studi Sistem Informatika, Sekolah Tinggi Teknologi Pagaralam \\ *febriansyahh1213@gmail.coml.com
}

\begin{abstract}
Abstrak
Penelitian ini bertujuan untuk menghasilkan Aplikasi Pencarian dan Pemesanan Hotel di Kota Pagar Alam berbasis web yang bisa mempermudah Pemilik Hotel dalam mengelola data dan juga mempermudah pihakpihak yang ingin mendapatkan informasi dengan cepat, serta bisa diakses kapan saja dan dimana saja. Pada Hotel di Kota Pagar Alam informasi mengenai Hotel saat ini masih manual, yaitu para pengunjung harus datang langsung ke Hotel Kota Pagar Alam untuk mencari informasi maupun melihat kondisi Hotel yang ada di Kota Pagar Alam sehingga pengunjung membutuhkan waktu yang lama untuk mencari informasi tentang Hotel, tujuan pembuatan aplikasi memudahkan user dalam melakukan pencarian dan pemesanan Hotel di Kota Pagar Alam sehingga user lebih mudah mencari informasi tentang Hotel Pagar Alam. Metode pengumpulan data dalam penelitian ini menggunakan metode wawancara, observasi, dokumentasi dan studi pustaka. Metode pengembangan Sistem menggunakan waterfall dengan tahapan Analisis, desain, pengkodean dan pengujian. Sistem ini dikembangkan dengan menggunakan aplikasi adobe dreamweaver CS3, Php, MySQL, dan Xampp. Hasil dari penelitian berupa Aplikasi Pencarian dan Pemesanan Hotel di Kota Pagar Alam berbasiis web.
\end{abstract}

Kata Kunci : Aplikasi, Hotel, Pagaralam, Waterfall, Website

\begin{abstract}
This study aims to produce Search and Booking Hotel Application in the city of Pagar Alam web-based which can facilitate Hotel Owners in managing data and also facilitate parties who want to get information quickly, and can be accessed anytime and anywhere. At Hotel in Kota Pagar Alam information about Hotel is currently still manual, namely visitors must come directly to Kota Pagar Alam Hotel to find information and see the condition of Hotel in Kota Pagar Alam so visitors need a long time to find information about Hotel, the purpose of making the application easier for users to search and book Hotel in the City of Pagar Alam so that users can more easily find information about the Hotel Pagar Alam. Data collection methods in this study use the method of interview, observation, documentation and literature study. The Sistem development method uses a waterfall with stages of analysis, design, coding and testing. This Sistem was developed using Adobe Dreamweaver CS3, PHP, MySQL, and Xampp applications. The results of the interim research in the form of Search and Booking Hotel applications in the City of Pagar Alam web-based
\end{abstract}

Keyword: Aplication, Hotel, Pagaralam, Waterfall, Website

\section{Pendahuluan}

Perkembangan teknologi yang semakin pesat sangat dibutuhkan karena banyak membawa pengaruh positif, saat ini perkembangan teknologi tidak bisa diragukan lagi karena sangat membantu dari segala aspek yang ada seperti hal nya di bidang Industri, Pemerintahan, ekonomi, sosial, pendidikan dan budaya, serta salah satunya yaitu dibidang pariwisata yang dimana dapat membantu dalam promosi maupun informasi Hotel yang ada dan dapat menyampaikan berita dengan cepat dan mudah. 
Web merupakan kumpulan halaman web yang dijalankan dari satu alamat web domain. Website digunakan untuk menampilkan informasi teks, gambar diam atau bergerak, suara, animasi, atau gabungan dari semuanya. Saat ini, Website dapat diakses menggunakan berbagi perangkat yang terhubung dengan internet, seperti laptop, Tabelt atau ponsel. (Nilasari, 2014).

Berdasarkan hasil penelitian melalui observasi dan wawancara pada beberapa pemilik Hotel di Kota Pagar Alam bahwa media promosi tentang informasi pada Hotel masih dilakukan secara manual. Para pengunjung biasanya mendapatkan informasi dari brosur atau bertanya kepada teman mereka yang ada di kota tersebut untuk mencari informasi tentang Hotel, hal ini dirasa kurang efektif dan efisien. Hotel itu sendiri merupakan suatu jenis akomodasi yang mempergunakan sebagian atau keseluruhan bangunan untuk menyediakan sebagai tempat untuk beristirahat, makan dan minum serta jasa lainnya seperti kepentingan umum, yang dikelola secara komersial, ataupun wisatawan yang sedang berkunjung ke suatu tempat yang memiliki beberapa destinasi wisata disebuah Daerah. Khususnya di Kota Pagar Alam, Gunung Dempo adalah daya tarik yang menjadi tujuan utama para wisatawan tidak hanya itu Kota Pagar Alam juga memiliki wisata-wisata lainnya yang menjadikan Pagar Alam sebagai kota wisata yang selalu ramai ketika hari libur atau hari besar tiba. Permasalahan yang perlu dihadapi dari pemilik Hotel maupun para wisatawan yang berkunjung ke Kota Pagar Alam yaitu bagaimana cara agar mereka bisa saling berinteraksi satu sama lain tanpa harus mendatangi lokasi Hotel atau bertemu pemilik secara langsung. Ada beberapa Hotel atau penginapan yang ada di Pagar Alam yang lokasinya lumayan jauh dari wisata. Oleh karena itu, untuk mengatasi masalah tersebut pengunjung harus mengetahui alamatalamat dari Hotel atau penginapan yang ada di Kota Pagar Alam agar dapat membandingkan lokasi, harga dan fasilitas dari Hotel tersebut.

Berdasarkan Penelitian terdahulu (Nababan, Putra, \& Hutagaol, 2019)Menyatakan bahwa Hotel yang dibangun harus berbasis web agar perubahan data terbaru dapat segera diketahui oleh berbagai pihak yang berkepentingan. Sedangkan menurut (Mubarok \& Apriyanta, 2017)dalam Penerapan Aplikasi Web di Hotel Arinda Guest House Bandung Hotel adalah industri yang berkembang sangat cepat seiring dengan perkembangan teknologi informasi. Metode yang digunakan untuk mengembangkan Software adalah metode Waterfall, yang dimulai dengan analisa kebutuhan disesuaikan dengan Sistem yang berjalan di Hotel arinda guest hous, design Sistem dan software, coding, testing dan implementasi. Sehingga penelitian ini menghasilkan Sistem informasi reservasi Hotel berbasis web. 
Dari beberapa penelitian terdahulu hubungan dengan penelitian yang dilakukan adalah samasama berkaitan dengan website juga membahas tentang promosi dan pemesanan Hotel, serta dapat memberikan kemudahan dalam pencarian alamat bagi wisatawan. Maka dari itu perancangan aplikasi pencarian dan pemesanan Hotel ini bertujuan untuk mempermudah pemilik dalam mempromosikan Hotel milik mereka serta kemudahan kepada para wisatawan yang mendapatkan informasi secara cepat dan akurat mengenai alamat, fasilitas dan harga dari Hotel tersebut

\section{Tinjauan Pustaka}

\subsection{Penelitian Terkait}

Dalam penuliasan penelitian ini, peneliti menggunakan literatur berupa penelitian sebelumnya yang berkaitan dan memiliki permasalahan yang sama, Adapun penelitian tersebut ialah :

Penelitian oleh Dhana Sudana, Atun Yulianto (2016) dengan judul Perancangan website Pondok permata Hotel dibangun mengikuti perinsip CMS (Content Managemen Sistem) dimana terdapat dua User yaitu pengunjung biasa artinya pengunung yang hanya dapat melihat informasi umum yang ditampilkan dalam website dan Administrator website adalah pemegang hak akses penuh atas update informasi.
Penelitian selanjutnya oleh Helda Yudiastuti (2017) dengan judul Sistem Informasi Reservasi Hotel dan Villa berbasis web pada Villa Seganti Etungguan Gunung Dempo Pagar Alam hasilnya Proses pemesanan kamar tamu sudah dapat langsung mengetahui jumlah kamar yang tersedia dan fasilitas lainnya yang mereka dapatkan tanpa harus datang langsung terlebih dahulu ke Hotel. Dengan adanya Sistem informasi reservasi kamar berbasis web dapat membantu mempermudah dan meminimalisir kesalahan staff Hotel khususnya bagian receptionist dalam mengelola data reservasi dan bermanfaat bagi pihak luar Hotel yangmembutuhkan informasi mengenai Hotel villa seganti setungguan gunung dempo.

Penelitian oleh Usman, Masdi (2018) dengan judul Aplikasi pencarian lokasi kos di kota Tambilahan berbasis web Mobile menghasilkan Aplikasi yang akan memanajemen data-data kos dan memberikan informasi kos secara detail dan lokasi yang akurat dengan memanfaatkan peta Google dan memberikan keuntungan bagi pengelola kos untuk memasarkan kos mereka kepada masyarakat luas

\subsection{Landasan Teori}

- Website

Website atau biasa yang disebut situs web atau situs adalah adalah media penyampai informasi di internet, terkadang disertai pula dengan 
berkas-berkas gambar, video, atau jenis-jenis berkas lainnya [9]. Sedangkan menurut Kamus Bahasa Inggris, "American Heritage" (2011) website adalah suatu halaman web yang saling berhubungan yang umumnya berada pada peladen (server) yang sama berisikan kumpulan informasi yang disediakan secara perorangan, kelompok, atau organisasi [10]. Web berdasarkan teknologinya terbagi menjadi dua, yaitu Web Statis dan Web Dinamis. Persamaan dari web statis dan web dinamis adalah keduanya merupakan suatu website yang menampilkan halaman yang ditampilkan di internet yang memuat informasi tertentu (khusus).

\section{Metode Penelitian}

Metode pengumpulan data yang dilakukan pada penelitian Hotel Kota Pagar Alam adalah sebagai berikut :

\section{a. Wawancara}

Wawancara adalah teknik pengumpulan data yang digunakan peneliti untuk mendapatkan keterangan-keterangan lisan melalui bercakapcakap dan berhadapan muka dengan orang yang dapat memberikan keterangan kepada si peneliti. [1]. Wawancara (Interview) dapat berupa wawancara personal (personal Interview) yang dilakukan secara pribadi, wawancara intersep (intercept Interview),wawancara telepon (telephone Interview) merupakan wawancara yang menggunakan alat komunikasi, dan wawancara terkontrol (controlled interview) wawancara yang telah dipersiapkan terlebih dahulu. Wawancara dalam penelitian ini dilakukan oleh peneliti dengan cara peneliti mengajukan pertanyaan kepada responden dengan pedoman wawancara, mendengarkan atas jawaban dan mengamati perilaku.

Tabel 1 : Instrumen Wawancara Pemilik Hotel

\begin{tabular}{|c|c|c|}
\hline No & Aspek & Pertanyaan \\
\hline 1. & $\begin{array}{l}\text { Proses } \\
\text { Berjalan }\end{array}$ & $\begin{array}{l}\text { a. Bagaimana Proses } \\
\text { Penyampaian } \\
\text { Informasi saat ini ? } \\
\text { b. Penyampaian } \\
\text { Informasi apakah } \\
\text { sudah berjalan dengan } \\
\text { baik? } \\
\text { c. Apakah proses manual } \\
\text { tersebut membuat } \\
\text { banyak kendala? } \\
\text { d. Seandainya ada orang } \\
\text { yang booking terus } \\
\text { membatalkan } \\
\text { bookingannya itu } \\
\text { bagaimana? }\end{array}$ \\
\hline 2. & $\begin{array}{l}\text { Jumblah } \\
\text { Pengunjung }\end{array}$ & $\begin{array}{l}\text { a. Berapa banyak } \\
\text { pengunjung yang } \\
\text { datang Perbulan? } \\
\text { b. Berapa banyak kamar } \\
\text { yang ada? } \\
\text { c. Berapa harga sewa } \\
\text { permalam,? }\end{array}$ \\
\hline 3. & $\begin{array}{l}\text { Usulan } \\
\text { Sistem }\end{array}$ & $\begin{array}{l}\text { Dari beberapa hal yang } \\
\text { mendasari kegagalan } \\
\text { diatas, apakah bapak } \\
\text { setuju apabila proses } \\
\text { pencarian dan pemesanan } \\
\text { Hotel menggunakan } \\
\text { Sistem berbasis web? }\end{array}$ \\
\hline
\end{tabular}

b. Observasi

Pengumpulan data dan informasi yang dibutuhkan dilakukan dengan mengamati 
langsung/survey ke Sistem yang sedang berjalan pada Hotel kota Pagar Alam.

Tabel 2. 2 : Instrumen Observasi

\begin{tabular}{|c|c|c|}
\hline No & Aspek & Indikator \\
\hline 1. & $\begin{array}{l}\text { Teknik } \\
\text { Pelaksanaan }\end{array}$ & $\begin{array}{l}\text { a. Media penyampaian } \\
\text { informasi Pencarian dan } \\
\text { Pemesanan Hotel } \\
\text { b. Proses pengumpulan } \\
\text { laporan } \\
\text { c. Proses Pemesanan } \\
\text { Hotel }\end{array}$ \\
\hline 2. & $\begin{array}{l}\text { Ketetapan } \\
\text { Proses }\end{array}$ & $\begin{array}{ll}\text { a. } & \text { Arah informasi } \\
\text { b. Kecepatan penyebaran } \\
\text { informasi } \\
\text { c. Keefektifan dan } \\
& \text { keefisienan proses }\end{array}$ \\
\hline
\end{tabular}

\section{c. Studi Pustaka}

Data diambil dari literatur buku-buku dan penelitian terdahulu yang relevan.

\section{d. Metode Pengembangan Sistem}

Metode SDLC air terjun (waterfall) sering juga disebut model sekuensi linier (sequential linier) atau alur hidup klasik (classic life cyle). Model air terjun menyediakan pendekatan alur hidup perangkat lunak secara sekuensial linier (sequential linier) atau alur hidup klasik (classic life cycle). Model air terjun menyediakan pendekatan alur hidup perangkat lunak secara sekuensial atau terurut dimulai dari analisi, desain, pengkodean, pengujian, dan tahapan pendukung. (support)..

Berikut adalah gambar model air terjun :

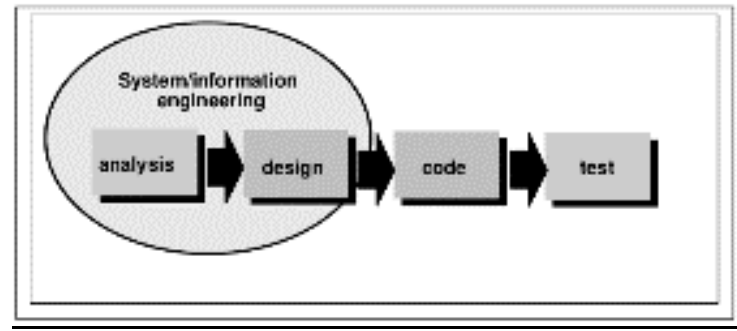

Gambar 1: llustrasi Model Waterfall

a. Analisis Kebutuhan Perangkat Lunak

Proses pengumpulan kebutuhan dilakukan secara intensif dalam pembuatan website agar dapat mempermudah User dalam mencari informasi dan memesan Hotel, Spesifikasi kebutuhan perangkat lunak pada tahap ini perlu untuk didokumentasikan.

\section{b. Desain}

Desain perangkat lunak adalah proses multi langkah yang fokus pada desain pembuatan program website. Tahap ini mentranslasi kebutuhan perangkat lunak dari tahap analisis kebutuhan ke representasi desain agar dapat diimplementasikan menjadi program pada tahap selanjutnya.

Use Case Diagram merupakan gambaran dari alur sebuah Sistem yang akan dibangun, terdiri dari beberapa actor, yaitu Admin (Dinas Pariwisata), Pemilik Hotel dan pengunjung. Dimana Admin, Pemilik Hotel dan User diharuskan melakukan Login dan di hadapkan pada beberapa menu pilihan. 


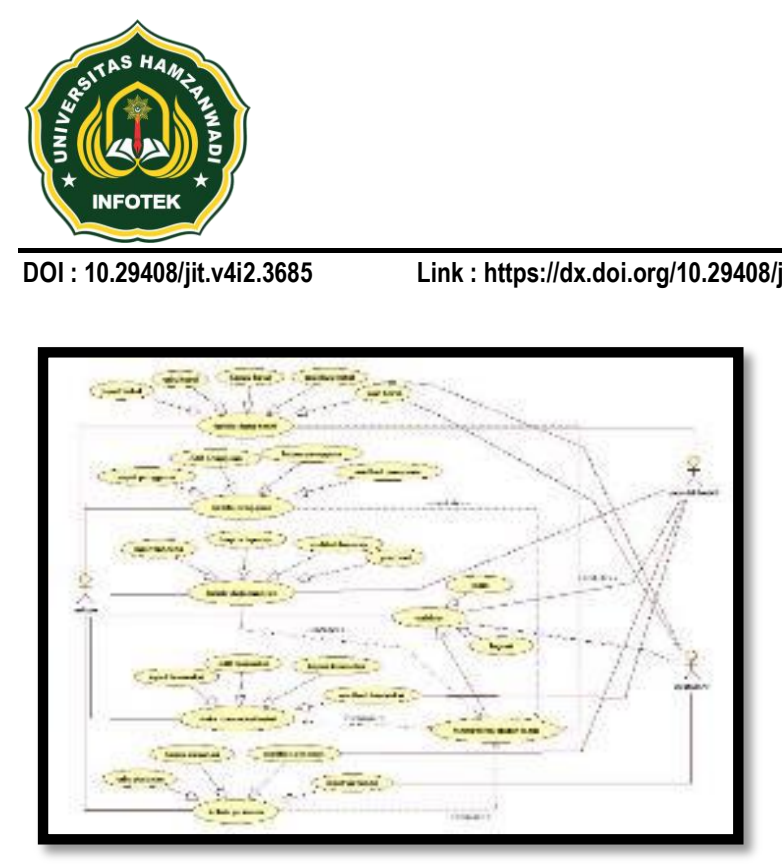

Gambar 2. Use Case Diagram

C. Pembuatan Kode Program

Desain harus ditranslasikan kedalam program website. Hasil dari tahap ini adalah sebuah website yang sesuai dengan desain yang telah dibuat pada tahap desain.

\section{d. Pengujian}

Pengujian fokus pada website secara dari segi logic dan fungsional dan memastikan bahwa semua bagian sudah diuji. Hal ini dilakukan untuk meminimalisir kesalahan (error) dan dapat mengimplementasikan keluaran yang sesuai dengan yang diinginkan

\section{Hasil dan Pembahasan}

a. Hasil

Hasil yang diperoleh dari penelitian ini adalah berupa aplikasi pencarian dan pemesanan hotel di Kota Pagar Alam berbasis web. Dengan adanya aplikasi pencarian dan pemesanan hotel ini dapat membantu pemilik hotel dalam mempromosikan dan mempermuda pemesanan lebih mudah dan efisien, kecepatan dan akurat dan memperoleh informasi pemesanan hotel
Infotek : Jurnal Informatika dan Teknologi

Vol. 4 No. 2, Juli 2021

Hal. 334-344

e-ISSN 2614-8773 yang diinginkan dan mempermudah user dalam memesan kamar hotel.

\section{b. Pengujian}

Dalam peneliitian ini peneliti menggunakan Black Box Testing (pengujian kotak hitam) yaitu pengujian perangkat lunak dari segi spesifikasi fungsional tanpa menguji desain dan kode program. Pengujian dimaksudkan untuk mengetahui apakah fungsi-fungsi, masukan dan keluaran dari perangkat lunak sesuai dengan spesifikasi yang dibutuhkan (A.S \& M, 2013).

Blac Box Testing (pengujian kotak hitam) yaitu pengujian perangkat lunak dari segi spesifikasi fungsional tanpa menguji desain dan kode program. Pengujian dimaksudkan untuk mengetahui apakah fungsi-fungsi, masukkan dan keluaran dari perangkat lunak sesuai dengan spesifikasi yang dibutuhkan. Pengujian kotak hitam dilakukan dengan membuat kasus uji yang bersifat mencoba semua fungsi dengan memakai perangkat lunak apakah sesuai dengan spesifikasi yang dibutuhkan (A.S.M.Shalahuddin, 2015).

c. Pembahasan

- Menu Utama

Rancangan Menu Utama Aplikasi Pencarian dan Pemesanan Hotel di Kota Pagar alam Berbasis web terdiri dari Home, Profil Hotel, Daftar Kamar Hotel , Tata Cara Pemesanan, Buku Tamu, 


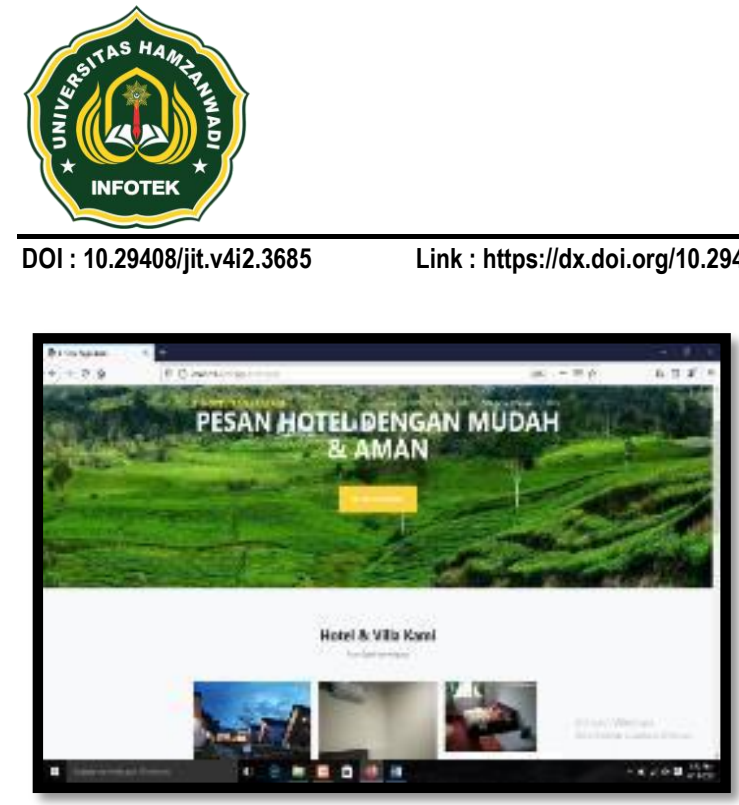

Gambar 3: Menu Utama

- Login User

Sebelum memesan user di haruskan untuk login dengan mengisi username dan password dengan benar demi keamanan semua pihak.

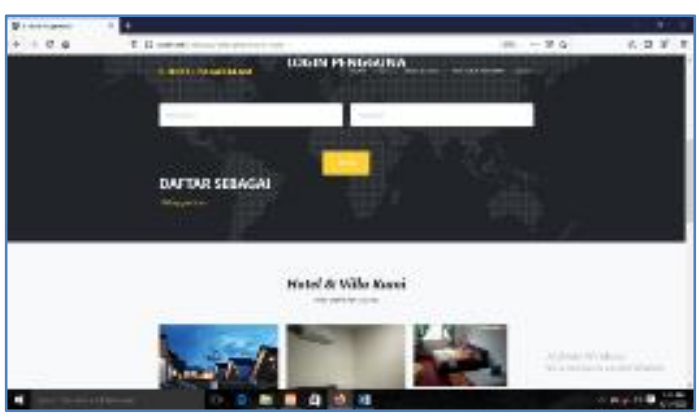

Gambar 5: Halaman Utama User

- Halaman Utama User

Halaman ini merupakan tampilan dari seluruh menu-menu website halaman Home merupakan halaman yang ditampilkan setelah user masuk login ke Sistem. Halaman ini memuat menu pilihan yang terdiri dari, Profil Hotel, Daftar Kamar Hotel, Tata Cara Pemesanan, Buku Tamu dan menu logout.

Infotek : Jurnal Informatika dan Teknologi

Vol. 4 No. 2, Juli 2021

Hal. 334-344

e-ISSN 2614-8773

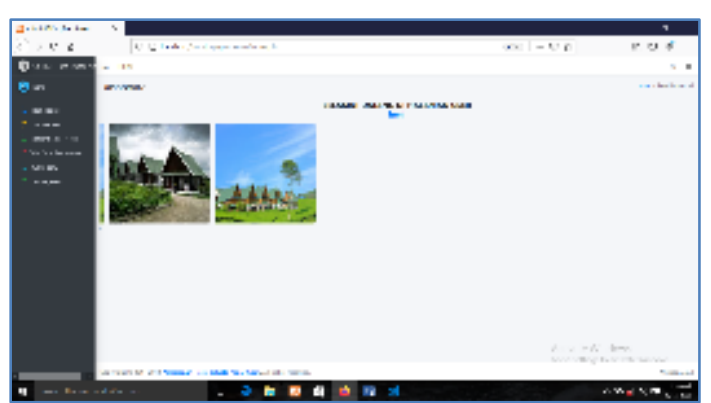

Gambar 6 : Halaman Setelah User Login

- Daftar Kamar Hotel

Halaman ini merupakan daftar kamar Hotel setelah login. User bisa melihat Hotel dan bisa langsung memesan Hotel, seperti gambar dibawah ini.

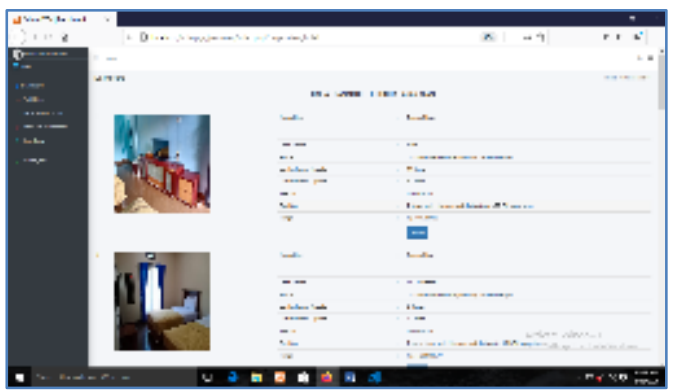

Gambar 8: Halaman Daftar Kamar Hotel Umum

User

\section{- Cetak Pesanan}

Halaman ini menampilkan mencetak bukti pemesanan Hotel user bisa melihat nomor rekening hotel untuk melakukan pembayaran dan untuk bukti pemesanan, seperti gambar dibawah ini.

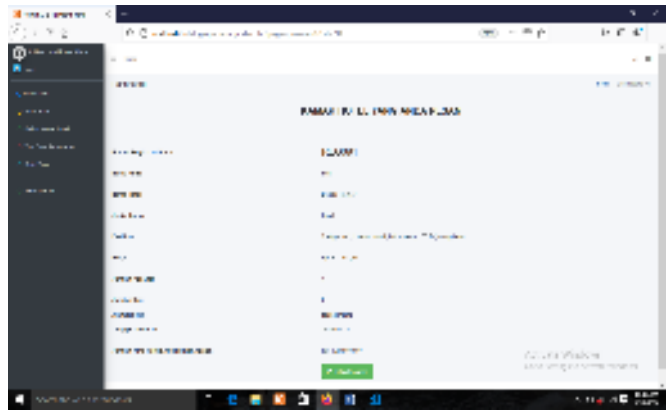


Gambar 1 Halaman Cetak User

- Pembayaran

Halaman ini merupakan tampilan halaman pembayaran user yang menampilkan jumlah pesanan, jumlah hari, tanggal masuk, jumlah bayar, tanggal masuk, status.

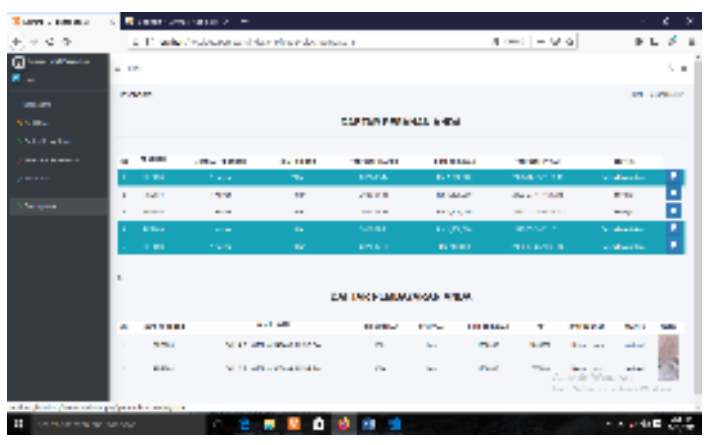

Gambar 10 Tampilan Pembayaran

- Menu Utama Mitra Hotel

Halaman ini merupakan tampilan Halaman setelah mitra Hotel login.

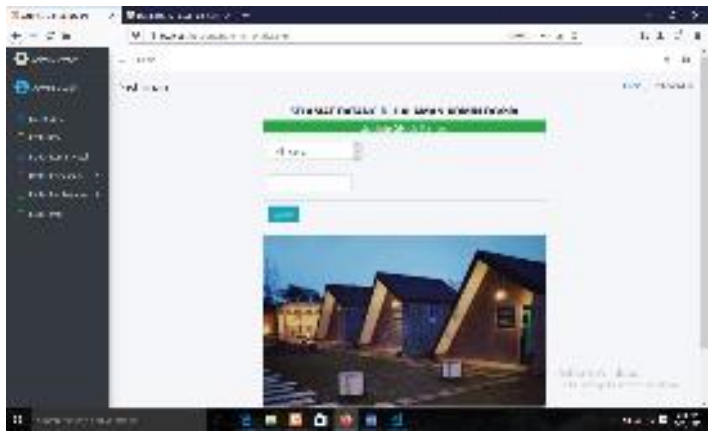

Gambar 12 Halaman Utama Mitra Hotel Setelah Login

- Daftar Pembayaran Yang Disetujui Mitra Hotel

Halaman ini merupakan halaman daftar pembayaran yang disetujui oleh mitra hotel.

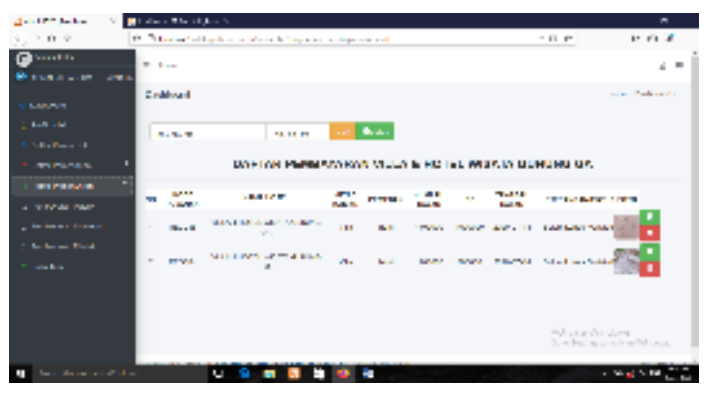

Gambar 13 Gambar Daftar Pembayaran Yang Disetujui Mitra Hotel

- Daftar Pemesanan Mitra Hotel

Halaman merupakan tampilan dari pemesanan kamar hotel mitra dimana hotel mitra dapat melihat pesanan yang masuk di aplikasi.

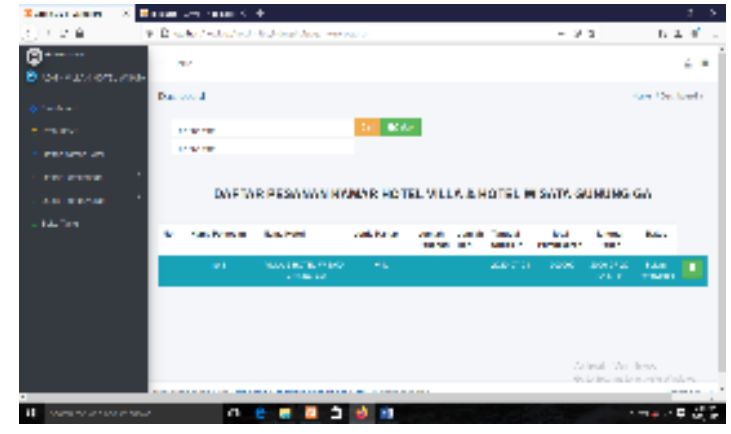

Gambar 14 Daftar Pemesanan Mitra Hotel

- Menu Utama Admin

Pada menu utama Aplikasi Pemesanan Hotel di Pagar Alam setelah Admin Login.

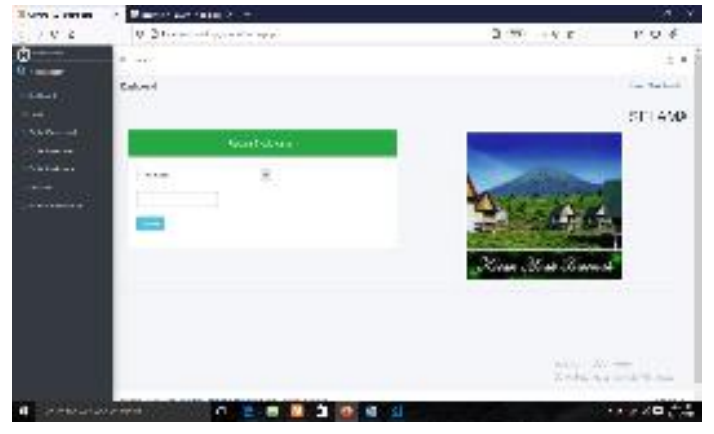

Gambar 15 Halaman Setelah Admin Login 
- Halaman Daftar Kamar Hotel Admin

Halaman ini merupakan tampilan dimana admin dapat mengelola daftar kamar hotel seperti yang tertampil pada gambar dibawah ini.

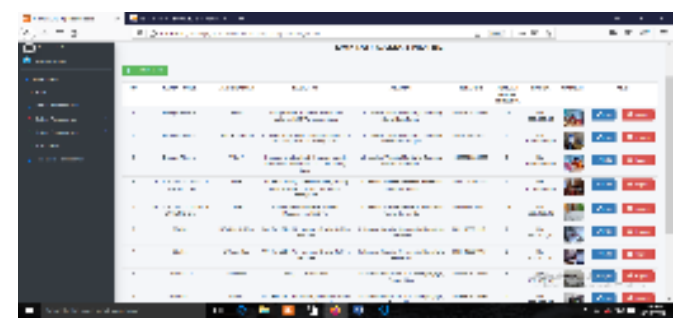

Gambar 16 Daftar Kamar Hotel Admin

- Daftar Pesanan Kamar Hotel Admin

Halaman ini menampilkan daftar pesan kamar hote.

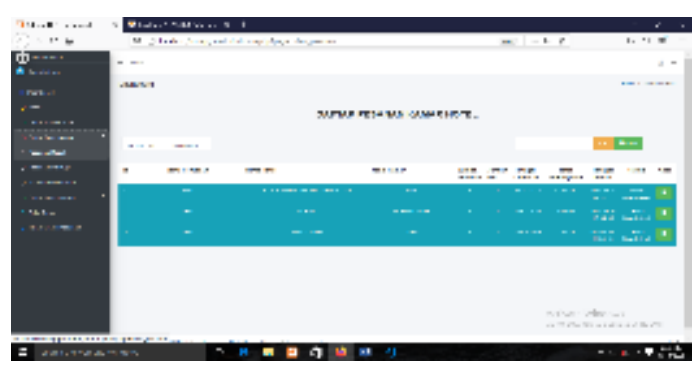

Gambar 17 Halaman Daftar Pesanan Kamar

Hotel Admin

- Daftar Pembayaran Kamar

Halaman ini menampilkan daftar pembayaran kamar hotel.

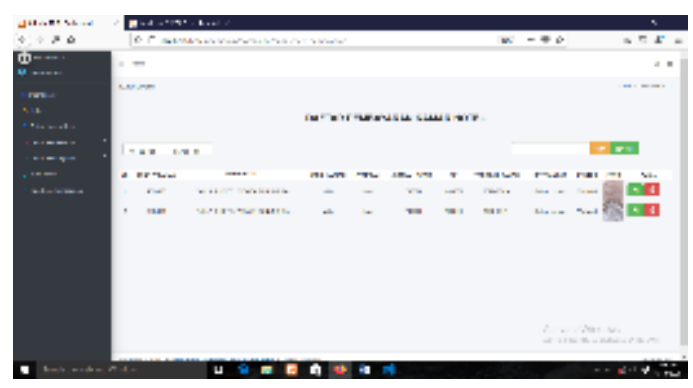

Gambar 18 : Daftar Pembayaran Kamar

\section{Kesimpulan}

Setelah membuat, mempelajari dan menganalisa aplikasi pemesanan kamar hotel berbasis web maka dapat diambil kesimpulan sebagai berikut :

1. Dengan adanya aplikasi pemesanan ini maka pihak hotel dapat mempromosikan kamar yang ditawarkan lewat website ini.

2. Dengan adanya aplikasi ini segala proses pengolahan data pemesanan dapat dilakukan dengan mudah dan cepat, karena Sistem pemasukkan data kamar dan Sistem pembuatan laporan telah dilakukan secara terkomputerisasi.

3. Aplikasi pencarian dan pemesanan hote di Kota Pagar berbasis web dapat dibuat dengan menggunakan pemrograman PHP, dan Database MySql

\section{Daftar Pustaka}

[1] S. Nilasari, "Jago Membuat Website Gratis Dan Cepat," Jakarta, Dunia Komputer, 2014, p. 2.

[2] M. N. Nababan, R. S. Putra dan N. A. Hutagaol, "Aplikasi Pemesanan Kamar Hotel Berbasis Android," Jurnal Sistem Informasi IImu Komputer Prima (JOSIKOM PRIMA) , 2019.

[3] A. Mubarok dan M. R. Apriyanta, "Penerapan Aplikasi Web Di Hotel Arinda Gues House Bandung," JURNAL INFORMATIKA, 2017.

[4] A. R. R. Hasan Abdurahman, "Aplikasi Pinjaman Pembayaran secara Kredit pada Bank Yudha Bhakti," Jurnal Computech \& Bisnis, pp. 61-69, 2014.

[5] A. Juansyah, "Pembangunan Aplikasi Child Tracker Berbasis Assisted - Global Positioning System (A-GPS)," Jurnal 
IImiah Komputer dan Informatika (KOMPUTA) , 2015.

[6] N. Hidayatun, M. Rosmiati dan E. Saputro, "Aplikasi E-Reservation Untuk Pemesanan Kamar Pada Hotel HIN'S," Jurnal Techno Nusa Mandiri, 2017.

[7] M. P. Lestari, "Sistem Informassi Reservasi Kamar Hotel Berbasis Web Pada Hotel Turtle Beach," 2016.

[8] S. M. Iskandar Sulaini, internet untuk pemula, Yogyakarta: Deepublish, 2014.

[9] R. A.S.M.Shalahuddin, dalam Rekayasa Perangkat Lunak Terstruktur Dan Berorientasi Objek, Bandung, Informatika Bandung, 2015.

[10] E. B. Zakarya dan H. Ummul, "sistem informasi pengelolaan data pendaftaran pada rumah rumah sakit sehat dompet," proseding seminar ilmu komputer dan teknologi informasi, pp. 1-4, 2017.

[11] M. Mundzir, "PHP tutorial book for beginner," dalam php tutorial book for beginner, Yogyakarta, 2014, p. 7.

[12] A. Fiki, perancangan sistem informasi manajemen (SIM) koperasi simpan pinjam tunas artha, p. 2, 2018.

[13] K. Abdul, "Mudah Mempelajari Database MySql," dalam Mudah Mempelajari Database MySql, Yogyakarta, 2009, p. 10.

[14] A. Fiki, Perancangan Sistem Informasi Manajemen (SIM) koperasi Simpan Pinjam Tunas Artha Mandiri (KSP TAM) Capem Tanjunganom Berbasis Web, p. 2, 2018.

[15] Sudianto Aris, "Penerapan Website Sebagai Sarana Promosi Wisata Budaya pada Kabupaten Lombok Timur," Infotek J. Inform. dan Teknol., vol. 1Sudianto, no. 1, pp. 11-17, 2018.

[16] I. Firli, Sistem Informasi E-commerce produk unggulan usaha mikro kecil menengah batik, p. 3, 2016.

[17] Andi, dalam Pemrograman PHP dan MYSQL, Yogyakarta, 2016.

[18] A. Sudianto and H. Ahmadi, "Rancang
Bangun Sistem Informasi Penjualan Sparepart Motor Pada Bengkel Vinensi Motor Berbasis Web Guna Meningkatkan Penjualan dan Promosi Produk Pendahuluan Vinensi sepeda motor motor," Infotek J. Inform. dan Teknol., vol. 3, no. 2, pp. 32-39, 2020 ..

[19] R. A.S dan S. M, dalam Rekayasa Perangkat Lunak Terstruktur dan Berorientasi Objek, Bandung, Informatika Bandung, 2013.

[20] D. Madalis, Metode Penelitian suatu pendekatan Proposal, Jakarta: BUMI AKSARA, 2004.

[21] P. D. Sugiyono, "Metode Penelitian Kombinasi (Mixed Methods)," Bandung, Alfabeta, 2011, p. 192.

[22] Putrawansyah, "Pengembangan Multimedia Interaktif Model Permainan Berbasis Android Pada Mata Pelajaran Tata Surya di Sekolah Menegah Atas," Jurnal Informatika, 2014.

[23] D. Mardalis, metode penelitian suatu pendekatan proposal, Jakarta: PT Bumi Aksara, 2004.

[24] E. H. Parmadi, A. R. Widiarti dan P. S. Adi, "Pengolaan Homestay Desa Wisata Pentingsari Berbasis Web," Prosiding Seminar Nasional penelitian dan pengabdian pada masyarakat, p. 386, 2017.

[25] D. Sudana dan A. Yulianto, "Perancangan Website Pondok Permata Homestay sebagai media informasi dan promosi," Indonesia JUrnal On networking and Security, p. 39, 2016.

[26] E. H. Parmadi, A. R. Widiarti dan P. S. Adi, "PENGELOLAAN HOMESTAY DESA WISATA PETINGSARI BERBASIS WEB," prosiding seminar nasional penelitian \& pengabdian pada masyarakat, pp. 387-386, 2017. 
[27] S. M. Sudianto Aris, "Penerapan Sistem Informasi Geografis (GIS) dalam Pemetaan Kerajinan Kain Tenun dan Gerabah untuk Meningkatkan Potensi Kerajinan di Kabupaten Lombok Timur," Infotek J. Inform. dan Teknol. J. Inform. dan Teknol., vol. 1, no. 2, pp. 64-71, 201.

[28] Putrawansyah, "Pengembangan Multimedia Interaktif Media Bermain Berbasis Android pada pelajaran tata," Jurnal Informatika, 2014.

[29] H. Yudiastuti, "Sistem Informasi Reservasi Hotel dan Villa berbasis Web pada Villa Seganti Setungguan Gunung Dempo Kota Pagar Alam," Prosiding Seminar Nasional Pendidikan Teknik Informatika , 2017.

[30] R. Abdulloh, Web Programming, Jawa Tengah: PT Gramedia Jakarta, 2016.. 